\title{
Factors with Impact in the Assessment and Choice of Tourist Destinations
}

\author{
Otilija Sedlak \\ University of Novi Sad, Faculty of Economics in Subotica, Serbia \\ Suzana Stojanović \\ University of Novi Sad, Faculty of Economics in Subotica, Serbia \\ Zoran Ćirić \\ University of Novi Sad, Faculty of Economics in Subotica, Serbia \\ Dušan Bobera \\ University of Novi Sad, Faculty of Economics in Subotica, Serbia
}

\section{Abstract}

The preference disaggregation approach to the problem of multicriteria choice is to uncover the inherent model of choice that brings a decision unit to a conclusion in terms of an overall preference on the alternatives. In the context, the actual market shares of a class of competing products (alternatives) constitute a concise global variable originated in and reflecting the cumulative preferences of the consumer body, which affects the pattern of the market. This paper presents a systematic method to analyse the preference information cumulated in the actual market shares of competing products in terms of the criteria involved in the process of choice. The aim of this study is to present an entirely new approach to the problem of multicriteria choice and an application to analyse the market of tourist agency destination offer. In the paper outlines the market share analysis methodology for building an additive utility model in situations concerning attributes on which preferences behave monotonically. When contemporary information and communication technologies are included into the processes of choosing then electronic word-of-mouth (e-WOM) communication appears, while specific marketing messages are being created and transferred. The paper ends with some concluding remarks.

Keywords: multicriteria decision making, tourist destinations, digitalisation, quantitative methods

JEL classification: C00, Z32, O31, M15

\section{Introduction}

Present-day tourist has special demands concerning performances of their tourism destinations due to gained wide experiences and possibilities for comparing touristic offers and relevant prices. The mentioned last issue is intensely supported by internet services. Using internet services modified application of word-of-mouth marketing (WOMM) - the so-called electronic word-of-mouth (eWOM), alternated market demand analysis, improved exploration of the satisfaction and awareness of clients and using of various methods of business promotion are enabled. One of the advantages of internet marketing is that companies are enabled to gain feedback information on products and services in real time, and so they can promptly react and focus to target groups of customers. Internet services are excellent basis for manifold data collection, contributing so to further development of marketing activities. Reality, however, is different: very often, we lack precise information on the value of individual 
input parameters, or the values of coefficients in constraint and goal functions, and imprecise formulation of limitations themselves is possible as well. The aim of the paper is to present the complexity of the problem: sustainable tourism means the ability of a tourist destination to remain competitive considering all of environmental and quality problems. The findings of our research can show that as source of information friends/family members, touristic organizations and internet sites can be used, while WOM communication appeared to be very important. For the majority of potential tourist rating sites are most important, followed by internet forums, social networks and finally internet blogs.

\section{Electronic Word of Mouth - EWOM}

Technological progress and internet have great influence on customer behaviour and modes of informing them about products, services, companies, persons and ideas. As to minimize/eliminate risk customers usually rely on experiences of others. Appropriate information is obtained through information by the means of word-of-mouth, to which a new dimension is added since internet is present. The communication between customers becomes digitalized, i.e. electronic word-of-mouth (eWOM) evolves. According to Hennig-Thurau et al. (2004) eWOM means "every either positive or negative opinion of present, potencial or former costomers about product, services or companies, that is available to multitude of other customers through internet services". The advantages of eWOM compared to the traditional WOM are high level of adaptability and prompt diffusion. In the case of eWOM not all participant is necessarily present in communication in the same time, internet services preserve information for a longer period, thus allowing later inclusion of some participants. This feature of eWOM enables easier measuring and analyzing of communication, compared to the traditional WOM technique. The difference between these two WOM methods is that that in traditional communication the information receiver knows the information provider, while in digitalized mode the source is usually unknown (Cheung and Thadani, 2012). Despite being impersonal, eWOM is a stronger communicationla tool for it is direct, credible, publicly accessible and thusmight have a wider influence (Hennig-Thurau et al., 2004). Electronic communication is very practical and eliminates problems of direct communication (Phelps et al., 2004); besides that, electronic communication encourages people to ask strangers for their opinion, while this is a rare situation in usual communication. Lack of information about the identity of the author is one of the shortcomings of eWOM (Kelly et al., 2010); this applies to electronic communication through internet forums and web pages when consumers are asked about their opinion on the purchased products. On-line users claim that information on products and services collected from other consumers through social networks are more valuable than those offered by marketing managers (Wang et al., 2011). Consumers are capable of making difference between online recommendations of authorities and of those given by other consumers, and believe the opinion of other consumers is more credible (Huang and Chen, 2006). Advantages of electronic WOM communication, which in the same time represent factors of promoting usage of personal messages (Lovett et al., 2013), are:

- Independency from company influence - higher level of persuasiveness of this source, for it offers complete and unbiased facts given by the third part.

- Experience transfer - Information acquired from costumers who possess their own experience contribute to risk reduction and in the same time spare time and money.

- High communication efficacy - Closeness and orientation are supported by personal messages. In direct personal communication, participants know each 
other, while by electronic means messages are being exchanged between totally unknown partners. This may represent a threat because credibility and truthfulness are sometimes questionable.

- Multiplication - Digital communication spares company's resources. eWOM is a marketing tool with great potentials, based on the conception of customer satisfaction, two-way communication and transparent and open communication. Promises of eWOM are especially important for small and medium enterprises, which have weaker access to commercial advertising.

Marketing system should be organized in such a way that it is capable of optimal achievement of defined objectives. This tusk will be fulfilled by restructuring of the traditional marketing communication strategies applying new definitions of objectives, new media choice and specifically new modes of marketing messages creation. Uncontrolled commercial in media should be replaced with marketing activities precisely aimed towards target groups like opinion leaders, experts, proponents and loyal customers; this contributes to cost reduction - because part of the efforts invested into distribution of information is transferred onto customers - and to the efficacy of the total communication activities of the company.

\section{Methodology}

Our investigation was performed based on the questionnaire "Impact of digitalization and communication between consumers on decision making about buying travel arrangement". The questionnaire is shown in Appendixl. We found out that visitors have opinions about tourist destinations. They posted them on leading travel blog sites were analyzed to gain an understanding of the destination experience being manifested (Pan et al., 2007). In the paper of Buhalis and Law we can find comprehensively reviews and analyses prior studies in the context of Internet applications to tourism (Buhalis and Law, 2009). We used some elements of their questionnaire about costumer tourist destinations choice.

Respondents gave grades from 1 (totally disagree) to 5 (totally agree) to the question about the significance of particular elements influencing decision making about touristic destinations. The higher the grade the higher is the importance of a particular factor for the tested subject. These elements were climate, safety, historical landmarks, entertainment/nightlife and festivals/ cultural events. In the next figure, the distribution of tested subjects dependent on the given grades is shown. The lower slice of any column shows the number of subjects who gave grade 1 to the importance of a factor, the next over it is the number of grades 2, and so on; the upper part is the number of answers with grade 5. The total number of answers adds up to 210 respondents for every factor. In the figure, the factors are ordered by the size of the average of the given grades.

\section{Results}

The random sample of respondents included 210 persons of which 151 (71.9\%) were females and 59 (28.1\%) were males. In the sample, 150 persons (71.4\%) were aged up to 35 years and the rest of $60(28.6 \%)$ were 36 years old or older. Answers to the question about the usual annual length of touristic travel dependent on their income were distributed as follows: 160 of the subjects (76.2\%) travel up to 15 days annually, 38 of them (18.1\%) between 16 and 25 days, and only 12 subjects (5.7\%) could afford to take a touristic travel over 25 days a year. Interesting is the fact that the number of respondents who organize their touristic travels by themselves is almost the same as the number of those who ask a touristic organization for help (49\%:51\%). 
It appears that the most important aspect for the tested subjects is safety when planning any travel, i.e. choosing a touristic destination; more than $90 \%$ of deliverers of opinion think safety is of extreme significance (grades 4 and 5), the overall average grade is very high and amounts to 4.54. The next element by importance for the tested tourists is climate, indicating the most often goals of travels, that are rest, leisure, summering or wintering holidays; this applies to $69 \%$ of respondents who gave grades 4 or 5 to this element. The average grade given to climate is 3.82 . The succeeding factors ordered by importance are historical landscapes (with average grade 3.53), then nightlife (2.69) and the last one is festivals (2.51). The result was that nightlife is of interest for one quarter of subjects and festivals for around one fifth of them (grades 4 and 5).

Figure 1

Distribution of Grades Given to the Significance of Factors Determining Decisions About Touristic Destinations

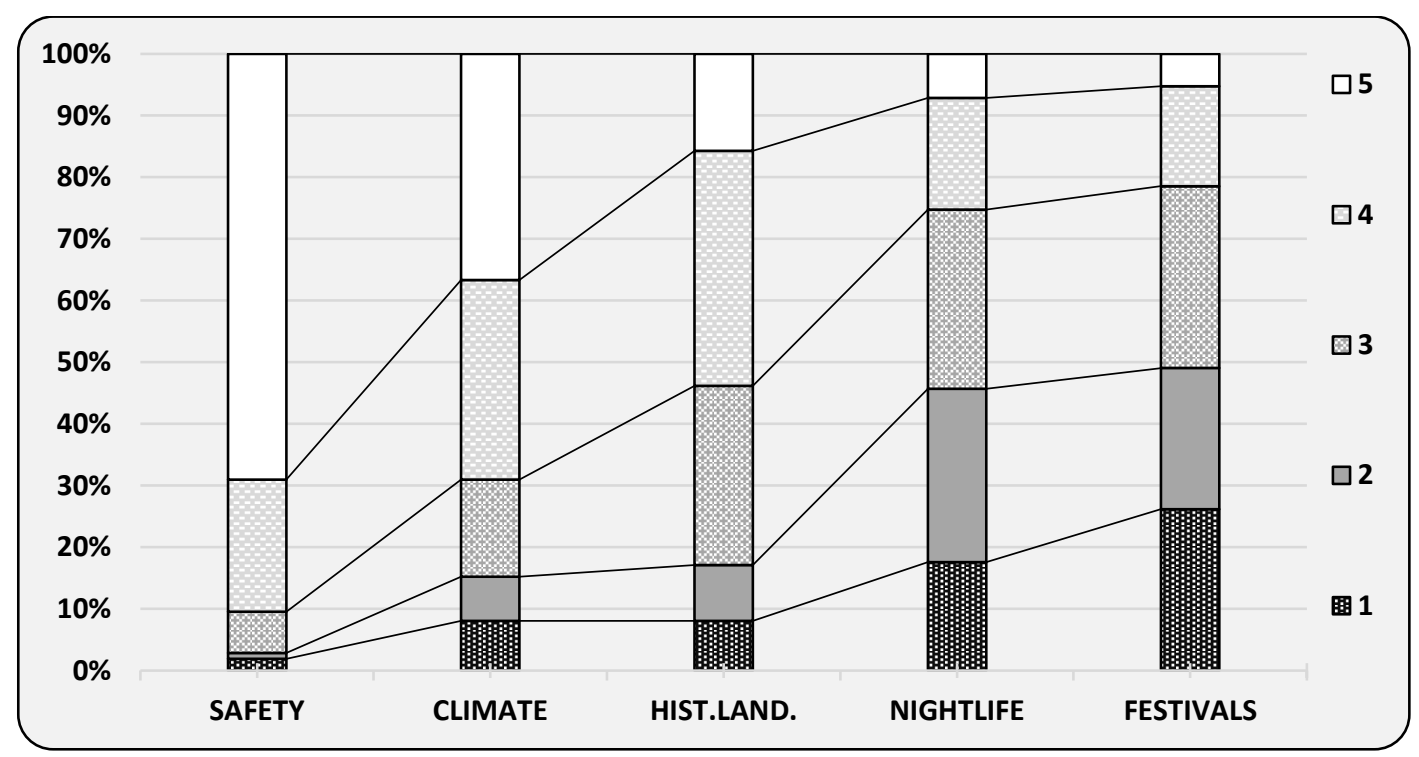

Source: Authors' illustration

Data on average grades of elements ordered by importance are shown in the next table.

Table 2

Average Grades of Decision-Making Factors

\begin{tabular}{llc}
\hline No. & \multicolumn{1}{c}{ Factor influencing decision making } & Average grade \\
\hline $\mathbf{1}$ & Safety & 4.54 \\
$\mathbf{2}$ & Climate & 3.82 \\
$\mathbf{3}$ & Historical landscapes & 3.53 \\
$\mathbf{4}$ & Nightlife & 2.69 \\
$\mathbf{5}$ & Festivals & 2.51 \\
& Overall average grade & 3.42 \\
\hline
\end{tabular}

Source: Authors' work

When analysing correlations between the age of respondents and significances of particular factors, it was found that there is some negative weak or minor linear relationship (although statistically significant) between age on one side and 
importance of nightlife and festivals on the other side. Spearman's correlation coefficient derived on basis of ranks $R h o=-0.29, p=0.000$ (weak relationship, highly significant) and Rho=-0.14, $p=0.043$, (minor relationship, significant) respectively, meaning older people rarely choose a touristic destination because of nightlife offers or festival events. Other decision-making elements do not have any significant correlation with the age of the respondents.

Also, the relation between sex and decision-making factors was investigated. The sole significant value was established for the relationship between the sex of the respondents and safety as a determinant factor when deciding about touristic destination. The linear relation is weak, the correlation coefficient highly significantly differs from zero (Rho $=0.24, p=0.004$ ). It appears that female tourists are somewhat more concerned about the safety on the chosen touristic destination than males.

The next question asked from respondents was in what extent they put their faith in either family members or friends' information about touristic destinations. Around one half of the respondents think they can rely on these information, one quarter is not convinced this would be a satisfactory source of information, while the rest of them (one quarter again) are hesitant. Average grade of answers amounts to 3.39. Some minor downhill linear relationship is found as well between the age of the subjects and the fact if they ask friends or family members for advice about touristic destination: older people more rarely ask for this kind of opinion than younger tourists, and rather rely on other sources of information, $(R h o=-0.197, p=0.004$, minor linear relationship, highly significant). Opinion number seven asked for from the respondents was related to the degree to which tourists can have confidence in touristic organizations concerning information about the destination, accommodation and touristic programs. It is somehow disappointing fact that the average grade is lower than one could expect and it amounts to 3.33. Around $61 \%$ of respondents are aware these information are credible (grades 4 and 5), we assume $9 \%$ of subjects giving lower grades ( 1 and 2) is too much. Similar is with the hesitant respondents (around 30\%), who are not fully convinced they can rely on touristic organizations, i.e. sometimes yes, sometimes not.

\section{Discussion}

Seeking for information about touristic organizations, destinations, accommodation, touristic programs etc. through electronic media was the next package of opinions expected the respondents to give. Hereby we tried to access how customers use internet services, i.e. eWOM, as source of data. The grades could be given were 1 (totally disagree) to 5 (totally agree). Respondents gave grades to the next four information sources: internet forums, internet blogs, rating sites and social networks.

The distribution of subjects giving different grades to particular internet sources is presented. The sources are ordered by the value of the average grade. The majority of the subjects use rating sites ( $65.7 \%$ of respondents gave grades 4 or 5 ); more than half of subjects also often use internet forums and social networks $154.8 \%$ and $51.0 \%$ respectively with grades 4 or 5 ) and the less popular is visiting internet blogs (only $37.1 \%$ with grades 4 or 5). This indicates people observe rating sites more reliable and trustful compared to other sources. 
Figure 2

Distribution of Grades Given to the Use of Internet Sources of Information About Touristic Destinations

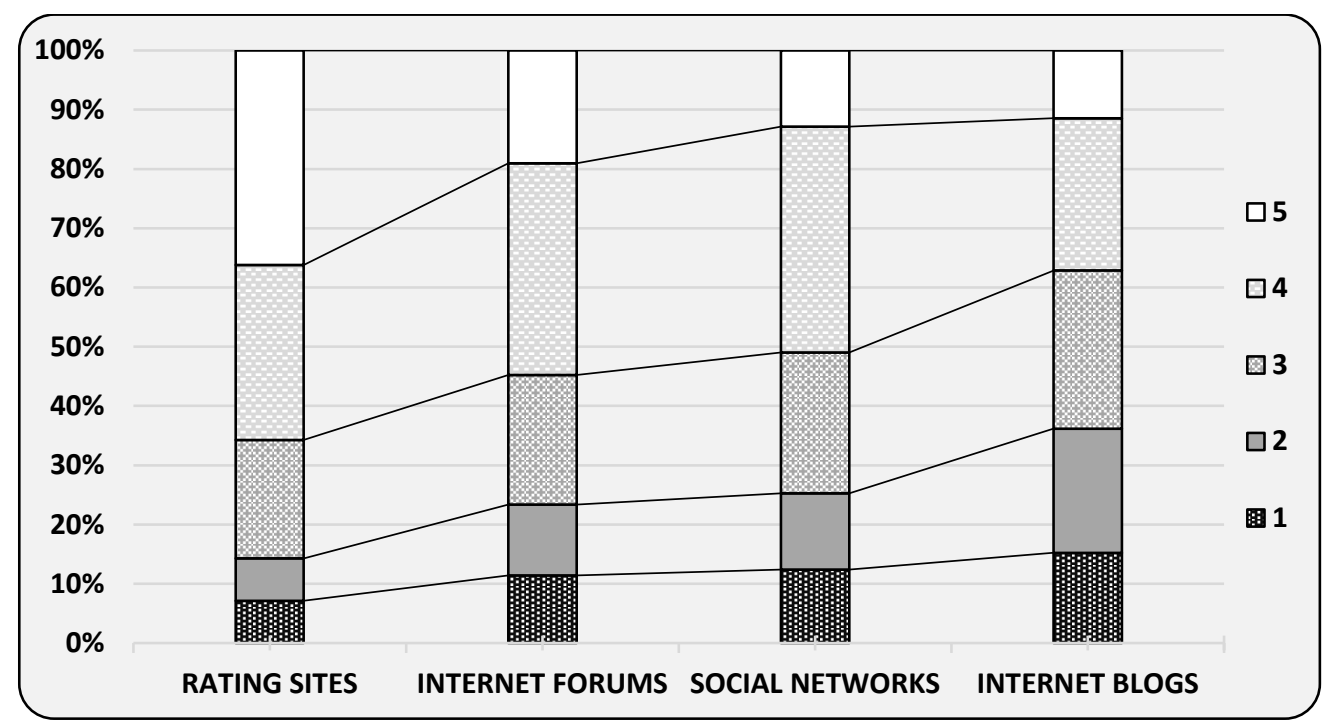

Source: Authors' illustration

Data on average grades of internet sources ordered by importance are shown in the next table.

Table 3

Average Grades of Internet Information Sources Use

\begin{tabular}{llc}
\hline No. & \multicolumn{1}{c}{$\begin{array}{c}\text { Internet services as sources of } \\
\text { information }\end{array}$} & Average grade \\
\hline 1 & Rating sites & 3.80 \\
2 & Internet forums & 3.39 \\
3 & Social networks & 3.26 \\
4 & Internet blogs & 2.97 \\
& Overall average grade & 3.36 \\
\hline
\end{tabular}

Source: Authors' work

On the other side, interesting is the number of subjects who think none of the internet sources is valuable/useful. The relative number of respondents who gave grade 1 to these sources are $7.1 \%, 11.4 \%, 1.24 \%$ and $15.2 \%$, while the overall average is $11.5 \%$, i.e. around one tenth of all customers usually refuse to use internet services as to get information connected to their touristic travels. The following block of questions in the questionnaire was related to the ease of access to information through internet services, reliability of information from internet sources, and comparability of information gathered from the internet with those obtained from other sources. 
Figure 3

Distribution of Grades Given to Ease of Access to Internet Services and Their Comparability and Reliability

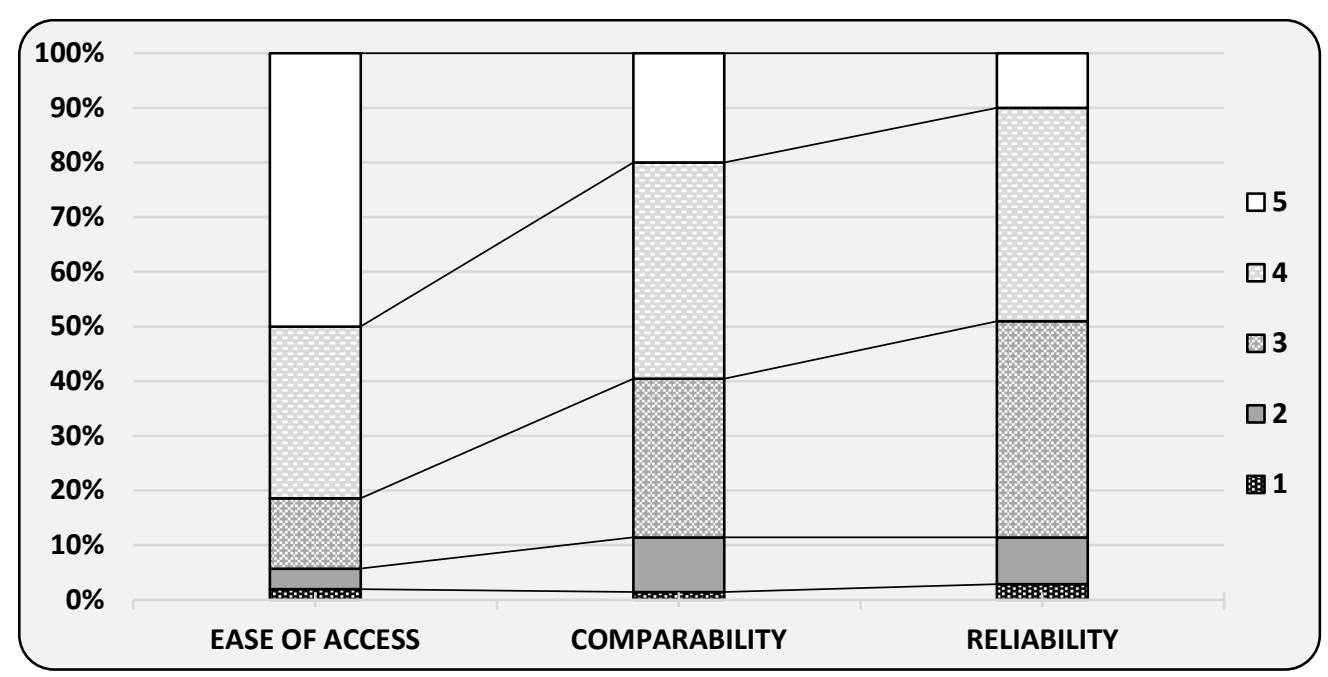

Source: Authors' illustration

Customers are aware of the presence and availability of internet services day and night and the possibility of accessing important information at any time and in any place, and they usually use its feature of quick and instantaneous access, choosing from a numerous of possible sites, even asking for automated help to find sites corresponding to their intents. According to this, tested subjects gave the high 4.24 average grade to this characteristic, over four fifth of the respondents place high significance to the ease of access to information from internet sources $181.4 \%$ with grades 4 or 5). When it is about the comparability of information from the internet with information gathered from other sources, the average grade is 3.67 , while $59.5 \%$ of respondents gave grades 4 or 5 . Not all are totally convinced the information from internet sources are fully objective and reliable. The average grade is 3.45 , and only around one half $(49.0 \%)$ of the tested subjects think they can completely rely on this source. Data on average grades of internet sources ordered by importance are shown in the next table.

Table 4

Average Grades of Internet Information Sources Use

\begin{tabular}{llc}
\hline No. & \multicolumn{1}{c}{ Features of internet services } & Average grade \\
\hline $\mathbf{1}$ & Ease of access to internet services & 4.24 \\
$\mathbf{2}$ & $\begin{array}{l}\text { Information from internet are comparable with other } \\
\text { information }\end{array}$ & 3.67 \\
3 & Internet sources are reliable and objective & 3.45 \\
\hline & Overall average grade & 3.78 \\
\hline
\end{tabular}

Source: Authors' work

\section{Conclusion}

Modern marketing managers and specialists are devoted to communications in general and particularly to word-of-mouth-communication, they all agree that WOM represents one of the strongest marketing tools in our times. Reasons why customers rely on information acquired from WOM communication is that they conceive media 
advertising is not always reliable, the amount of information is so abundant there is not enough time at disposal to evaluate them, presence of so-called customer-controlled media, etc. Statistical research shows the topics of almost one third of all communication are products and services. WOM marketing is not intended to replace the traditional marketing. It is a new way of thinking about marketing, pointing to creation of such marketing activities that form better and more effective relations with customers. WOM is not an isolated marketing technique. WOM represents a marketing philosophy, which relies on principles of customer satisfaction and transparent and mutual dialogs with them.

In this paper, results of research about information sources and factors of determining touristic destination are presented. The research was conducted through a questionnaire completed by 210 respondents. When choosing touristic destinations, customers always collect information about travel, accommodation, conditions and characteristics of the location. The results of our investigation showed that as source of information friends/family members, touristic organizations and internet sites can be used, while WOM communication appeared to be very important. Factors influencing decision-making about touristic destinations showed different importance; safety is on the first place (particularly for female subjects), and then follow climate and historical landscapes; nightlife and festivals are of less general importance, except for younger people.

\section{References}

1. Buhalis, D., Law, R. (2009), "Progress in information technology and tourism management: 20 years on and 10 years after the Internet - The state of e-Tourism research". Tourism Management, Vol. 29, No. 4, pp. 609-623.

2. Cheung, C. M. K., Thadani, D. R. (2012), "The impact of electronic word-of-mouth communication: A literature analysis and integrative model", Decision Support Systems, Vol. 54, No. 1, pp. 461-470.

3. Hennig-Thurau, T., Gwinner, K., Walsh G., Gremler D. (2004), "Electronic word-of-mouth via consumer-opinion platforms: What motivates consumers to articulate themselves on the Internet?", Journal of Interactive Marketing, Vol. 18, No. 1, pp. 38-52.

4. Huang, J., Chen, Y. (2006), "Herding in online product choice", Psychology and Marketing, Vol. 23, No. 5, pp. 413-428.

5. Kelly, L., Kerr, G., Drennan, J. (2010), "Avoidance of advertising in social networking sites: the teenage perspective", Journal of Interactive Advertising, Vol. 10, No. 2, pp. 16-27.

6. Lovett, M. J., Peres, R., Shachar, R. (2013), "On brands and word of mouth", Journal of Marketing Research, Vol. 50, No. 4, pp. 427-444.

7. Pan, B., MacLaurin, T., Crotts, C. J. (2007), "Travel Blogs and the Implications for Destination Marketing", Journal of Travel Research, Vol. 46, No. 1, pp. 35-45.

8. Phelps, J. E., Lewis, R., Mobilio, L., Perry, D., Raman, N. (2004), "Viral marketing or electronic word-of-mouth advertising: Examining consumer responses and motivations to pass along email", Journal of advertising research, Vol. 44, No. 4, pp. 333-348.

9. Wang, M. H., Huang, C. F., Yang, T. Y., Wu, Y. N. (2011), "The effects of online consumer information adoption on purchasing decision", availabe at:

http://www.marketing_trendscongress.com/archives/2011/Materiali/Paper/Internet/Y ang_Yang_Huang.pdf. (4 April 2019). 


\section{About the authors}

Otilija Sedlak is a full professor at the University of Novi Sad, Faculty of Economics Subotica, working within the Department of Business Informatics and Quantitative Methods. She is involved in the realization of the teaching process on basic studies, master studies as well as on PhD studies in subjects close to her scientific interests: Operational research, Financial and actuary mathematics, Mathematics for economists, Quantitative methods in economy and management, Risk management. She published several scientific papers in international and national journals and participated in many scientific international conferences. The author can be contacted atso0609967@gmail.com.

Suzana Stojanović, Ph.D. student is an Assistant Professor at the College of Applied Professional Studies, Vranje, Serbia, Department of Management and Business. She is PhD studentat the Faculty of Economics in Subotica, University of Novi Sad, Department of Management and Business. She finished Master studies at the Faculty of Economics in Subotica, Department of Finance, Banking and Insurance. Her main research interests are information and communication technology, innovation. Suzana Stojanović published several scientific papers in international and national journals and participated in scientific international conferences. The author can be contacted at suzana93stojanovic@gmail.com.

Zoran Ćirić is an associate professor at the University of Novi Sad, Faculty of Economics Subotica, working within the Department of Business Informatics and Quantitative Methods. He is involved in the realization of the teaching process on basic studies, master studies as well as on PhD studies in subjects close to his scientific interests: Management information systems, Project management, Business process, Knowledge management. He published several scientific papers in international and national journals and participated in many scientific international conferences. The author can be contacted at zoran.ciric@ef.uns.ac.rs.

Dušan Bobera is a full professor at the University of Novi Sad, Faculty of Economics Subotica, working within the Department of Management. He is involved in the realization of the teaching process on basic studies, master studies as well as on PhD studies in subjects close to his scientific interests: Project Management, Entrepreneurship and Management of Innovation, Management of Investments and Projects. He published several scientific papers in international and national journals and participated in many scientific international conferences. The author can be contacted at bobera@ef.uns.ac.rs. 


\section{APPENDIX}

\section{Table 2}

Questionnaire "Impact of Digitalization and Communication between Consumers on Decision Making About Buying Travel Arrangement"

\author{
1. Sex \\ 2. Age
}

3. Dependent on your income how long can you stay annually at a touristic destination?

4. When planning your travel you

Please give a grade to the next statements (choose only one answer): 1 - totally disagree; 2 - disagree; 3 - unsure; 4 - agree; 5 - totally agree

5a. When deciding about my travel, then climate is important for me

5b. When deciding about my travel, then safety is of great importance for me

5c. When deciding about my travel, then historical landmarks are important for me

5d. When deciding about my travel, then nightlife is important for me

5e. When deciding about my travel, then festivals are important for me

6. When deciding about my travel I ask my family or my friends for information about the touristic destination

7. When deciding about my travel I assume information about the destination, accommodation and touristic programs given by touristic organizations are credible

8a. When deciding about my travel I seek for information on internet forums

8b. When deciding about my travel I seek for information on internet blogs

8c. When deciding about my travel I seek for information on internet pages connected to evaluation of accommodation, touristic agencies and the destination (rating sites)

8d. When deciding about my travel I seek for information on social networks

9a. Information about the touristic destination, accommodation and agencies are most conveniently accessible through internet services

9b. Information about the touristic destination, accommodation and agencies found on the internet are reliable

9c. Information about the touristic destination, accommodation and agencies found on the internet are comparable to information collected from other sources 